\title{
The Endovascular Management of Superior Cerebellar Artery Aneurysms
}

\author{
Charles Haw, Robert Willinsky, Ronit Agid, Karel TerBrugge
}

\begin{abstract}
Background: Superior cerebellar artery aneurysms are rare. We present a clinical series of twelve of these aneurysms that were treated exclusively with endovascular coils. Method: A retrospective analysis of a prospectively collected database of cerebral aneurysms treated with coil embolization was performed. Clinical notes and radiological images were reviewed. Results: Twelve superior cerebellar artery aneurysms were treated in eleven patients between 1992 and 2001. Seven patients presented with subarachnoid hemorrhage, two with neurologic deficit, and two had asymptomatic aneurysms. Coiling resulted in complete aneurysm obliteration in six patients and incomplete obliteration in the other six. No subsequent hemorrhage occurred with follow-up between 6 and 119 months (mean follow-up 50 months). Procedural morbidity was one superior cerebellar artery infarct with good recovery. Management morbidity was one middle cerebral artery embolus during a follow-up angiogram that required thrombolysis with a good clinical result. Nine out of 11 patients on follow-up were performing at Glasgow Outcome Scale (GOS) 5. One patient with GOS 3 presented with a poor grade subarachnoid hemorrhage and the other patient with GOS 4 presented with a parenchymal hemorrhage due to an arteriovenous malformation. Conclusion: Endovascular treatment of superior cerebellar artery aneurysms is an effective treatment strategy with low morbidity.
\end{abstract}

RÉSUMÉ: Le traitement endovasculaire des anévrismes de l'artère cérébelleuse supérieure. Introduction: Les anévrismes de l'artère cérébelleuse supérieure sont rares. Nous présentons une série clinique de douze cas de ces anévrismes qui ont été traités exclusivement par coils endovasculaires. Méthode: Il s'agit d'une analyse rétrospective d'une base de données recueillies de façon prospective, d'anévrismes cérébraux traités par embolisation de coils. Nous avons revu les observations cliniques et les images radiologiques. Résultats: Douze anévrismes de l'artère cérébelleuse supérieure ont été traités chez onze patients entre 1992 et 2001. Le mode de présentation était celui d'une hémorragie sous-arachnoïdienne chez sept patients, d'un déficit neurologique chez deux et les deux autres avaient des anévrismes asymptomatiques. La mise en place de serpentins a complètement oblitéré l'anévrisme chez six patients et incomplètement chez six autres. Aucune hémorragie subséquente n'a été observée pendant un suivi de 6 à 119 mois. (suivi moyen de 50 mois). La morbidité associée à l'intervention a été la suivante: un infarctus de l'artère cérébelleuse supérieure qui a bien récupéré. Une embolie de l'artère cérébrale moyenne pendant un angiogramme de suivi a nécessité une thrombolyse avec de bons résultats cliniques. Neuf des onze patients avaient un score de 5 à l'échelle de Glasgow (ÉG). Un patient dont le score ÉG était de 3 présentait une hémorragie sous-arachnoïdienne à mauvais pronostic et l'autre patient, dont le score était de 4, présentait une hémorragie parenchymateuse due à une malformation artério-veineuse. Conclusion: Le traitement endovasculaire des anévrismes de l'artère cérébelleuse supérieure est une stratégie thérapeutique efficace qui comporte une morbidité faible.

Can. J. Neurol. Sci. 2004; 31: 53-57

Reports describing the efficacy of endovascular therapy for superior cerebellar artery (SCA) aneurysms are rare and are usually found in reports of clinical series describing the endovascular management of basilar artery aneurysms or posterior circulation aneurysms. ${ }^{1-3}$ We describe the endovascular management of our clinical series of superior cerebellar artery aneurysms and review the literature on the topic.
From the Division of Neuroradiology, Toronto Western Hospital, University of Toronto, Toronto, Ontario, Canada.

ReCeived May 22, 2003. ACCEPTED In Final FORm August 21, 2003. Reprint requests to: Robert Willinsky, Fell Pavilion 3-210, 399 Bathurst Street, Toronto, ON M5T 2S8 Canada. 

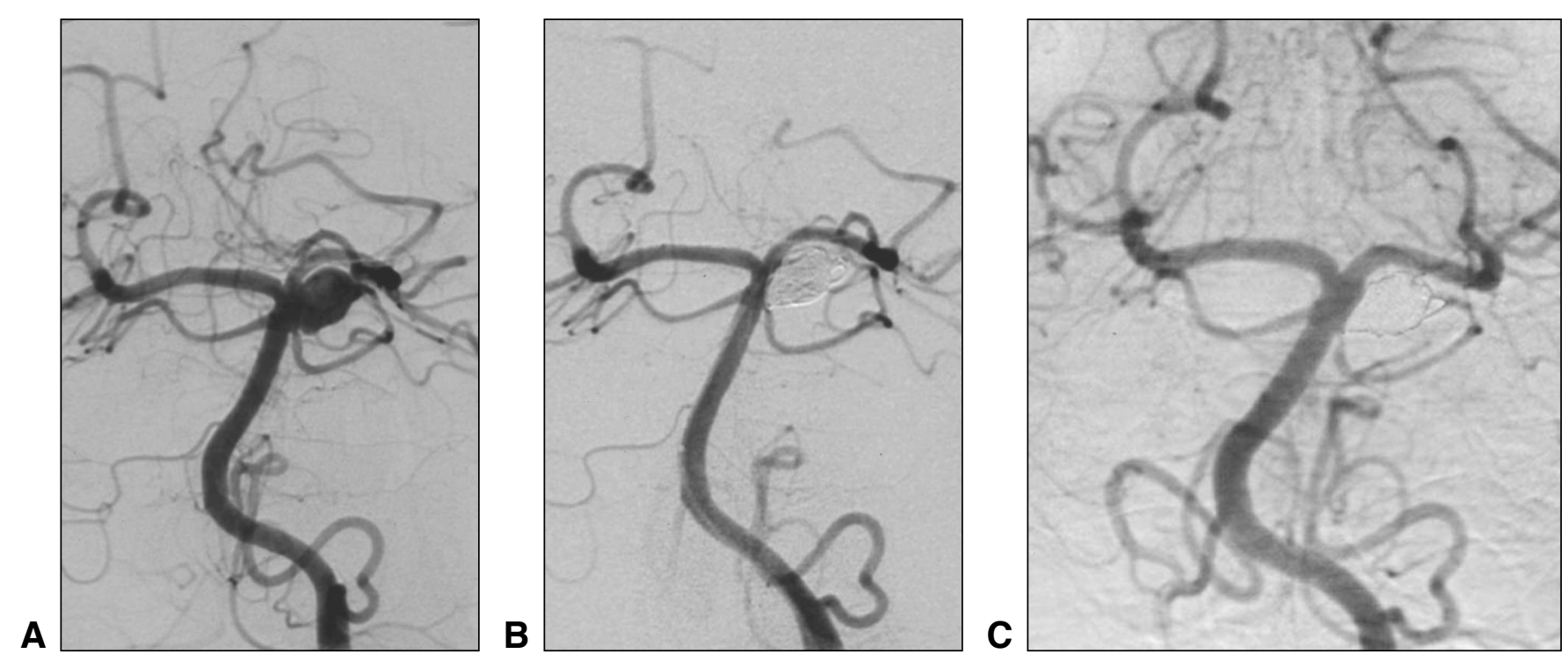

Figure: Left vertebral artery injections showing a ruptured left superior cerebellar artery aneurysm with a wide neck and poor dome:neck ratio. (A) pretreatment, (B) near the end of the coiling procedure, (C) 45 month follow-up showing persistent total occlusion

\section{METHODS}

The Toronto Western Hospital has a prospectively collected database of 285 cerebral aneurysms managed by endovascular coiling from October 1992 to March 2003. This prospective database was reviewed retrospectively for all superior cerebellar artery aneurysms. All related clinical records and radiologic images were reviewed. Clinical follow-up consisted of chart review as well as telephone interviews when required.

The endovascular coiling procedure has been previously well-described. Briefly, all cases started with general anesthesia and femoral sheath placement. The patient was systemically heparinized with a $100 \mathrm{U} / \mathrm{kg}$ intravenous heparin bolus followed by a $1000 \mathrm{U}$ bolus/hour during the procedure. A 5 or 6 French guide catheter was selectively placed in the cervical segment of the vertebral artery that gave better vascular access. Projections best displaying the aneurysm neck were chosen, in the majority of cases, with the aid of three dimensional spin angiography. Under roadmap guidance, a microcatheter was coaxially placed through the guide catheter and over a microwire into the aneurysm sac. Guglielmi detachable coils (Boston Scientific) were used for aneurysm occlusion (Figure). At the end of the procedure, the heparin was discontinued but not reversed with protamine.

\section{Results}

\section{Patient characteristics}

Twelve superior cerebellar artery aneurysms were treated with endovascular coils in 11 patients between 1992 and 2001 (Table 1). One patient who presented with subarachnoid hemorrhage had bilateral superior cerebellar artery aneurysms. There were six females and five males with an age range between 40 and 74 years. Seven patients presented with subarachnoid hemorrhage, two had cranial nerve III paresis, and two had asymptomatic aneurysms. One of the latter two patients had a screening examination due to a strong family history of cerebral aneurysms; the other patient presented with an intracerebral hematoma from a left parietotemporal arteriovenous malformation. The patients presenting with aneurysmal subarachnoid hemorrhage were generally in good neurologic condition with 5/7 in World Federation of Neurological Surgeons Grades I or II, one patient was Grade III, the last patient was Grade IV. ${ }^{4}$

\section{Aneurysm characteristics}

Of the 12 aneurysms, six were right-sided and six were leftsided (Table 2). Eleven of the 12 aneurysms arose at the origin of the superior cerebellar artery from the basilar artery. One rightsided aneurysm arose at the first bifurcation of the superior cerebellar artery. Nine of the treated aneurysms were small with a maximum dimension less than or equal to 10 millimeters (mm). Three aneurysms had a maximum dimension greater than 10 $\mathrm{mm}$. Eleven aneurysms had neck sizes less than $5 \mathrm{~mm}$. However, because of the overall small aneurysm size in this series, 8/12 aneurysms had calculated dome:neck ratios less than $2 .{ }^{5}$ Five out of twelve aneurysms showed incorporation of the superior cerebellar artery into the aneurysm neck.

\section{Results of endovascular therapy}

At the end of the embolization procedure, six aneurysms were completely occluded and six had neck or neck/body residual. Three of the eight aneurysms with dome:neck ratio less than 2 were incompletely occluded; $3 / 4$ of the aneurysms with dome:neck ratio greater than or equal to 2 were incompletely occluded. However, one of the latter aneurysms incorporated the 
Table 1: Patient Characterisitics

\begin{tabular}{|c|c|c|c|c|c|c|c|c|c|}
\hline Patient & Age & Presentation & WFNS & Initial Exam & Complication & $\begin{array}{c}\text { Catheter angio } \\
\text { MRA) FU (months) }\end{array}$ & $\begin{array}{l}\text { Clinical FU } \\
\text { (months) }\end{array}$ & GOS & Persisting deficit \\
\hline 1 & 62 & SAH & II & Normal & no & 23 & 68 & 5 & No \\
\hline 3 & 40 & Asymptomatic & NA & Dysphasia & no & 8 & 101 & 4 & Dysphasia \\
\hline 4 & 60 & SAH & II & Normal & $\begin{array}{l}\text { R MCA embolus, } \\
\text { thrombolysis }\end{array}$ & 45 & 45 & 5 & No \\
\hline 5 & 70 & Neuro deficit & NA & CN 3 palsy & no & 6 & 72 & 5 & No \\
\hline 6 & 47 & Neuro deficit & NA & CN 3 palsy & no & 25 & 119 & 5 & No \\
\hline 7 & 42 & SAH & I & Normal & no & 4 & 12 & 5 & No \\
\hline 8 & 74 & SAH & II & CN 3 palsy & no & 0 & 6 & 5 & No \\
\hline 11 & 61 & SAH & III & $\begin{array}{l}\text { Motor, speech } \\
\text { deficit }\end{array}$ & Lt. SCA infarct & 6 & 6 & 5 & No \\
\hline
\end{tabular}

FU=follow-up; WFNS=World Federation of Neurological Surgeons; GOS=Glasgow Outcome Scale; NA=not applicable

\begin{tabular}{|c|c|c|c|c|c|c|c|}
\hline Patient & Side & $\begin{array}{l}\text { Aneurysm Size } \\
(\mathbf{m m})\end{array}$ & $\begin{array}{l}\text { Neck Size } \\
\quad(\mathbf{m m})\end{array}$ & Dome:neck ratio & $\begin{array}{c}\text { SCA } \\
\text { Incorporation }\end{array}$ & $\begin{array}{l}\text { Residual } \\
\text { post embo }\end{array}$ & $\begin{array}{c}\text { Residual } \\
\text { on FU }\end{array}$ \\
\hline 1 & $\mathrm{~L}$ & $4.8 \times 3.5$ & 2 & 1.75 & Yes & neck & neck \\
\hline 2 & $\mathrm{R}$ & $9 \times 3 \times 3$ & 1 & 3 & No & no & no \\
\hline 3 & $\mathrm{R}$ & $2.7 \times 2.1$ & 1.5 & 1.4 & No & neck/body & no \\
\hline 5 & $\mathrm{R}$ & $11 \times 5.9 \times 5.8$ & 2.5 & 2.36 & Yes & neck & neck \\
\hline 6 & $\mathrm{~L}$ & $10 \times 5.3 \times 6$ & 3 & 2 & No & neck & neck/body \\
\hline 7 & $\mathrm{R}$ & $3.4 \times 1.7$ & 1.5 & 1.1 & Yes & no & no \\
\hline 8 & $\mathrm{~L}$ & 16 & 4 & 4 & No & minimal body filling & \\
\hline 11 & $\mathrm{~L}$ & $6.9 \times 4.6$ & 3 & 1.5 & Yes & no & no \\
\hline
\end{tabular}

$\mathrm{SCA}=$ superior cerebellar artery 
SCA origin and aneurysm residual was left on purpose to avoid parent artery compromise. Follow-up catheter angiograms were performed on 10/12 aneurysms. Of the completely occluded aneurysms, 5/6 had follow-up angiography and 4/5 demonstrated persistent total occlusion. One of five developed a neck and body residual which has not been retreated. One of six patients did not have follow-up angiography due to advanced age and poor neurologic condition. Of the incompletely occluded aneurysms, $5 / 6$ had follow-up angiography. One of five progressed to complete aneurysm occlusion. Four of five had persistent residuals. One patient in this group with progressive aneurysm recanalization had aneurysm retreatment with coils. One of six patients did not have follow-up angiography due to advanced age and has been lost to follow-up. One patient had follow-up magnetic resonance angiography after the initial follow-up catheter angiogram had demonstrated persistent total occlusion.

Of the five aneurysms showing incorporation of the SCA origin, 2/5 were incompletely occluded and 3/5 were completely occluded. One of these latter three was complicated by parent artery compromise and stroke.

Over a mean 50 month follow-up (range 6 - 119 months), no new or recurrent subarachnoid hemorrhage has occurred. The two patients presenting with cranial neuropathy showed resolution of their findings. Nine of $11(82 \%)$ patients have attained Glasgow Outcome Scale (GOS) 5. One patient is GOS 4 due to an arteriovenous malformation related parenchymal hematoma and resultant dysphasia. The last patient is GOS 3 due to severe peripheral vasospasm resulting in bilateral posterior cerebral artery infarcts, cortical blindness, and seizures.

\section{Complications}

One of 11 patients $(9 \%)$ developed a complication directly due to the endovascular coiling. A patient with a left SCA aneurysm demonstrating incorporation of the SCA origin had the aneurysm completely occluded but suffered a left SCA territory infarct due to parent artery compromise. He developed left limb cerebellar findings but in long term follow-up has made a complete recovery.

One of 11 patients (9\%) suffered a right middle cerebral artery bifurcation embolus during a follow-up diagnostic cerebral angiogram. This was treated with intra-arterial thrombolysis and the patient made a complete recovery within 24 hours.

\section{Discussion}

There are few reports documenting the results of SCA aneurysm endovascular coiling. Uda et $\mathrm{al}^{3}$ described their results in 41 basilar trunk aneurysms of which thirteen were SCA aneurysms. Eight patients presented with subarachnoid hemorrhage, two with mass effect, and three were incidental findings. Five aneurysms were coiled completely and eight had neck residual. Six of these eight aneurysms had wide necks which was defined as greater than or equal to $4 \mathrm{~mm}$. Dome:neck ratio and parent artery incorporation was not reported. During a mean 25 month follow-up, of these eight, two demonstrated further aneurysm occlusion, three had recanalization, and one was unchanged on follow-up angiography. Two of these eight patients did not have angiographic or clinical follow-up. Of the five completely occluded aneurysms, three were stable and two did not have clinical or angiographic follow-up. No new or recurrent subarachnoid hemorrhage was seen. Similar to our series, 10/13 patients had excellent outcome.

Pierot et $\mathrm{al}^{1}$ described their results of coil embolization in 35 basilar artery aneurysms. Five were SCA aneurysms, and all presented with subarachnoid hemorrhage. The aneurysms were small (defined as less than $15 \mathrm{~mm}$ ), and they were completely occluded at the end of the endovascular procedure. There was no mention of neck size, dome:neck ratio, or parent artery incorporation. Long term results were durable and the patients had excellent outcomes. No rebleeding occurred, however the follow-up period was short with three patients having follow-up less than or equal to four months.

Two other sizable series of SCA aneurysms have been reported. Vinuela et $\mathrm{al}^{6}$ published a multicentre study describing coil embolization of ruptured aneurysms in 403 patients. There were $16 \mathrm{SCA}$ aneurysms in that cohort but no specific information is available about them. Lempert et $\mathrm{al}^{2}$ reported the results of coil embolization in 112 posterior circulation aneurysms. Approximately 12 SCA aneurysms were coiled and follow-up angiography in seven showed greater than $90 \%$ occlusion. Otherwise, no other specific information is available.

Our results are similar to $\mathrm{Uda}$ et $\mathrm{al}^{3}$ in that a significant number of the aneurysms were not completely occluded by endovascular coiling. We believe that this is due to two factors. Aneurysms with dome:neck ratios less than 2 can be difficult to coil completely and may be impossible to coil due to coil prolapse into the parent artery. ${ }^{5}$ Eight of 12 aneurysms in this series had dome:neck ratios less than 2. Aneurysm incorporation of the parent artery origin can make complete coiling difficult or impossible. ${ }^{7}$ Five of the 12 aneurysms in this series showed incorporation of the SCA origin.

Despite the presence of incompletely coiled aneurysms, there has been no new or recurrent subarachnoid hemorrhage in this series or in the series of Uda or Pierot. The majority of patients in these series have done well. However, SCA aneurysms with poor dome:neck ratios or those that incorporate the parent artery are predisposed to incomplete coil occlusion. Long term clinical follow-up is required since new or recurrent subarachnoid hemorrhage has been reported from residual aneurysms after endovascular therapy. .8

The International Subarachnoid Aneurysm Trial (ISAT) prospectively randomized 2,143 patients with subarachnoid hemorrhage from a ruptured intracranial aneurysm to either surgery or endovascular therapy. The study reported a $6.9 \%$ absolute risk reduction in poor outcome at one year with endovascular therapy. ${ }^{10}$ Although ISAT enrolled only five SCA aneurysms, we feel it currently provides the best available evidence that ruptured SCA aneurysms should preferentially be coiled, based on the improved outcomes in the endovascular group. The ISAT also indicates that endovascular treatment prevents short and medium term rehemorrhage. Surgery or repeat coiling of a residual aneurysm could be performed in selected cases. ${ }^{11}$ Surgery for unruptured SCA aneurysms is preferred when endovascular coiling would likely leave a significant residual due to a poor dome:neck ratio or incorporation of the parent artery. We believe that a multidisciplinary team of neurosurgeons and endovascular therapists should manage cerebral aneurysms to ensure the best possible outcome. 


\section{REFERENCES}

1. Pierot L, Boulin A, Castaings L, Rey A, Moret J. Selective occlusion of basilar artery aneurysms using controlled detachable coils: report of 35 cases. Neurosurgery 1996; 38:948-954.

2. Lempert TE, Malek AM, Halbach VV, et al. Endovascular treatment of ruptured posterior circulation cerebral aneurysms. Clinical and angiographic outcomes. Stroke 2000; 31:100-110.

3. Uda K, Murayama Y, Gobin P, Duckwiler GR, Vinuela F. Endovascular treatment of basilar artery trunk aneurysms with Guglielmi detachable coils: clinical experience with 41 aneurysms in 39 patients. J Neurosurgery 2001; 95:624632.

4. Drake C. Report of World Federation of Neurological Surgeons Committee on a universal subarachnoid hemorrhage grading scale. J Neurosurgery 1988; 68:985-986.

5. Debrun GM, Aletich VA, Kehrli P, et al. Selection of cerebral aneurysms for treatment using Guglielmi detachable coils: the preliminary University of Illinois at Chicago experience. Neurosurgery 1998; 43:1281-1297.

6. Vinuela F, Duckwiler GR, Mawad M. Guglielmi detachable coil embolization of acute intracranial aneurysm: perioperative anatomical and clinical outcome in 403 patients. J Neurosurgery 1997; 86:475-482.

7. Regli L, Dehdashti AR, Uske A, de Tribolet N. Endovascular coiling compared with surgical clipping for the treatment of unruptured middle cerebral artery aneurysms: an update. Acta Neurochir Suppl 2002; 82:41-46.

8. $\mathrm{Ng} \mathrm{P,} \mathrm{Khangure} \mathrm{MS,} \mathrm{Phatouros} \mathrm{CC,} \mathrm{et} \mathrm{al.} \mathrm{Endovascular} \mathrm{treatment} \mathrm{of}$ intracranial aneurysms with Guglielmi detachable coils. Analysis of midterm angiographic and clinical outcomes. Stroke 2002; 33:210-217.

9. Malisch TW, Guglielmi G, Vinuela F, et al. Intracranial aneurysms treated with the Guglielmi detachable coil: midterm clinical results in a consecutive series of 100 patients. J Neurosurgery 1997; 87:176-183.

10. International Subarachnoid Aneurysm Trial (ISAT) Collaborative Group. International Subarachnoid Aneurysm Trial (ISAT) of neurosurgical clipping versus endovascular coiling in 2143 patients with ruptured intracranial aneurysms: a randomised trial. Lancet 2002; 360:1267-1274.

11. Zhang JY, Barrow DL, Cawley CM, Dion JE. Neurosurgical management of intracranial aneurysms previously treated with endovascular therapy. Neurosurgery 2003; 52:283-295. 